\title{
Optimization of Electromagnetic Devices Using a RSM Enhanced $\mathrm{ACO}_{\mathrm{R}}$ Algorithm
}

\author{
Anton Duca* and Bianca Lamba* \\ *Politehnica University of Bucharest, Bucharest, Romania, anton.duca@upb.ro
}

DOI: 10.52846/AUCEE.2021.1.06

\begin{abstract}
The present paper proposes and studies the efficiency of using a RSM enhanced $\mathrm{ACO}_{\mathrm{R}}$ algorithm for the optimization of electromagnetic devices. Different RSM methods, such as Box-Behnken, CCD and Doelhert, are applied to find most suitable parameters (optimal set) for the $\mathrm{ACO}_{\mathrm{R}}$ in order to solve the corresponding electromagnetic optimization problems. The parameters optimal set is found by building a metaheuristic function. In the same time, the optimal parameter set is searched and determined for each electromagnetic problems for different objective functions, the best and the average global best solution for a tests set. The electromagnetic devices to be optimized are the Loney's solenoid and an energy storage device, as defined by the TEAM22 problem. Both electromagnetic problems are proposed benchmarks from electromagnetic community.
\end{abstract}

Cuvinte cheie: calcul evoluţionist optimizare, $A C O_{R}, R S M$, Box-Behnken, CCD, Doelhert, electromagnetic, TEAM22, solenoidul lui Loney.

Keywords: Evolutionary Computation, Optimization, $A C O_{R}$, RSM, Box-Behnken, CCD, Doelhert, Electromagnetic, TEAM22, Loney's solenoid.

\section{INTRODUCTION}

Proposed in [1] by Dorigo and collaborators, AS (Ant System), like any ant algorithm, is an evolutionary algorithm initially designed for hard non-determinist polynomial problems such as QAP [2] [3], TSP [2] [3] [4] or MKP [5] [6]. The algorithm simulates the search for food behavior by the ant colonies. The process uses the pheromone concept, a substance which is secreted by ants on theirs search paths for food.

To improve the performances of the AS algorithm several solutions have been proposed in the literature, the most effective and known are the ACO (Ant Colony Optimization) [3] and the MMAS (Min-Max Ant System) [2]. Along with algorithms created for combinatorial problems, solutions designed for continuous problems were proposed, like the $\mathrm{ACO}_{\mathrm{R}}$ (ACO for real / continuous domains) [7].

Just as any other evolutionary computation algorithm, the $\mathrm{ACO}_{\mathrm{R}}$ performance strongly depends by the parameters of the algorithms and, of course, by the optimization problem [8]. To find the $\mathrm{ACO}_{\mathrm{R}}$ set of optimal parameters for solving electromagnetic benchmark problems, the present paper studies and proposes the possibility of using the RSM (Response Surface Methodology) [9].

Originally proposed during 1950s in [10] by Box et al. the RSM was targeting statistics and design of experiments. The RSM is a set of mathematical and statistical techniques sequentially applied to map empirical models and / to data, data obtained and provided by experimental designs.

Since proposed, the RSM has been successfully applied independently or embedded in other algorithms to solve various problems from different domains as computer science [4], chemistry [11] or electrical engineering [12] [13] [14].

In the current study, several RSM models, such as BoxBehnken [15], CCD (Central Composite Design) [10] and Doelhert [16] are applied to improve the $\mathrm{ACO}_{\mathrm{R}}$ 's performances when optimizing electromagnetic devices. The performance tuning is done by searching the optimal set of parameters for the $\mathrm{ACO}_{\mathrm{R}}$. The problems to be solved are TEAM22 (Testing Electromagnetic Analysis Method) [17] and Loney's solenoid [18], two benchmarks proposed by the electromagnetic community.

\section{THE $\mathrm{ACO}_{\mathrm{R}}$ ALGORITHM}

The $\mathrm{ACO}_{\mathrm{R}}$ is an ant based algorithm for continuous domains proposed by Socha and Dorigo in [7].

Like any other $\mathrm{ACO}$ algorithm, $\mathrm{ACO}_{\mathrm{R}}$ is population based but unlike the other algorithms it stores the pheromones table as an archive of solutions (Fig. 1).
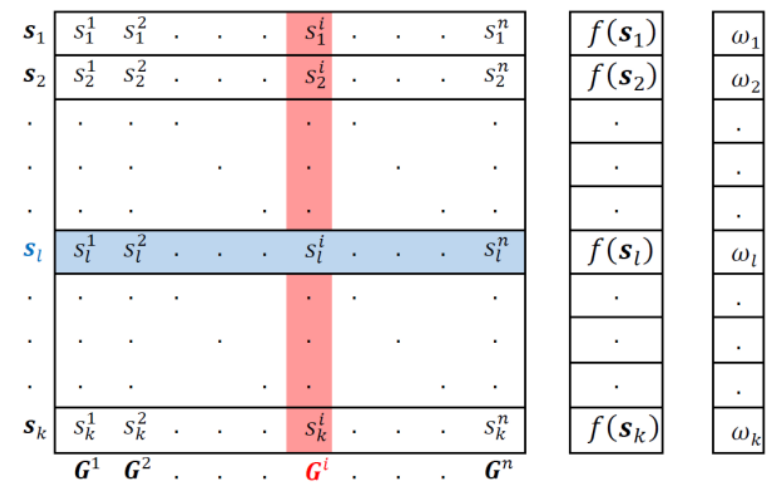

Fig. $1 . \mathrm{ACO}_{\mathrm{R}}$ archive (size $k$ ): solutions $\boldsymbol{s}_{l}$, fitness values $f\left(\boldsymbol{s}_{l}\right)$, weights $\omega_{l}$, search space size $n$, Gaussian kernels $\boldsymbol{G}^{i} i=(1, n)$.

The archive is sorted using the fitness values of the solutions $\left(f\left(\boldsymbol{s}_{l}\right)<f\left(\boldsymbol{s}_{l+1}\right)\right)$, where $f: \Omega \subset \mathrm{R}^{\mathrm{n}} \rightarrow \mathrm{R}$ represents the $\mathrm{OF}$ (objective function). For each solution there is a weight $\omega$ related to its fitness measure $\left(\omega_{l}>\omega_{l+1}\right)$.

The weight for a solution $s_{l}$ is calculated as:

$$
\omega_{l}=\frac{1}{q k \sqrt{2 \pi}} e^{-\frac{(l-1)^{2}}{2 q^{2} k^{2}}},
$$

where $q$ is a parameter of the $\mathrm{ACO}_{\mathrm{R}}$ algorithm called the locality of the search process and $k$ is the size of the archive of solutions. When $q$ is small the weights for better ranked solutions are bigger, whereas when $q$ is large the weights are more uniform. 
If in the case of PSO and GA, where a particle or an individual encapsulates a solution, for ACO algorithms an ant is a solution builder. To construct a new solution an ant starts from a solution $l$ from the archive. The $l$-th solution is chosen with a wheel probability mechanism:

$$
p b_{l}=\omega_{l} / \sum_{j=1}^{k} \omega_{j}
$$

The construction of the new solution is performed in $n$ steps. At step $i$ the value for the corresponding variable is calculated using information which only regards the dimension $i$. The value of the variable is generated randomly by a Gaussian distribution:

$$
G_{l}^{i}(x)=\frac{1}{\sigma_{l}^{i} \sqrt{2 \pi}} e^{-\frac{\left(x-\mu_{l}^{i}\right)^{2}}{2 \sigma_{l}^{i^{2}}}},
$$

where $\mu$ and $\sigma$ are the mean and the standard deviation of the Gaussian kernel.

For the evaluation of the parameters the archive of solutions is used as follows:

$$
\begin{gathered}
\mu_{l}^{i}=s_{l}^{i}, \\
\sigma_{l}^{i}=\xi \sum_{e=1}^{k}\left|s_{e}^{i}-s_{l}^{i}\right| /(k-1),
\end{gathered}
$$

where $\xi$, the convergence rate, is the fourth $\mathrm{ACO}_{\mathrm{R}}$ parameter, equivalent with the pheromone evaporation from the ACO algorithm. If $\xi$ is smaller the exploitation is dominant comparing to exploration, so the convergence speed is faster.

After a solution set (size equals the number of ants) is constructed, the solutions are evaluated, added to the archive, and sorted according to their fitness values. Afterwards, the worst solutions are removed in order to keep an imposed value for the archive of solutions. In the end the weights are updated accordingly with the new archive.

The pseudocode of the $\mathrm{ACO}_{\mathrm{R}}$ algorithm is [8]:

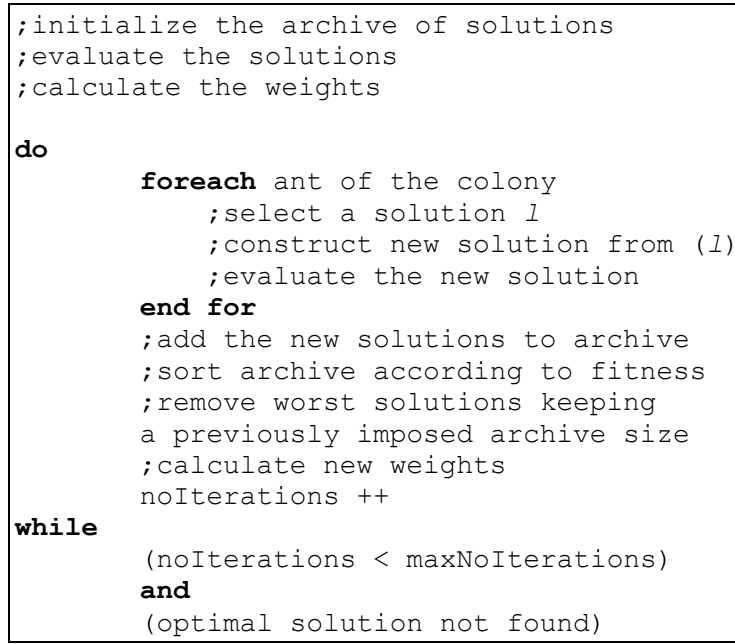

More explanations and details about $\mathrm{ACO}_{\mathrm{R}}$ are available in [7].

\section{THE RSM ENHANCEMENT}

The main idea behind using RSM to enhance the $\mathrm{ACO}_{\mathrm{R}}$ performance is the building of a metaheuristic function $g$ with the purpose of finding the optimal set of $\mathrm{ACO}_{\mathrm{R}}$ pa- rameters when solving benchmark electromagnetic problems. The metaheuristic function is quadratic, $g: R^{n p} \rightarrow R$ , a choice which proven to offer good results [12] [20] when approximating functions with unknown landscapes, like in our case:

$$
\begin{aligned}
g\left(p_{1}, p_{2}, \ldots p_{n p}\right) & =c_{0}+\sum_{i=1}^{n p}\left(c_{i} \cdot p_{i}+c_{i i} \cdot p_{i}^{2}\right) \\
& +\sum_{i, j=1}^{n p} c_{i j} \cdot p_{i} \cdot p_{j},
\end{aligned}
$$

where $n p$ is the number of $\mathrm{ACO}_{\mathrm{R}}$ parameters, $p=\left[p_{1}, p_{2}\right.$, $\left.\ldots p_{n p}\right]$ are the parameters (variables) of the $g$ function, and $c$ the coefficients. The parameters of $g$ are the scaled versions of the ACO parameters (the number of ants, the locality of the search process, the size of the archive and the convergence speed), whereas the return value corresponding to a point (set of parameters) in the definition domain is a measurement of fitness related to the objective function of the problem to be solved.

The optimal set of parameters is found in four steps:

- A number of points in the parameters space are generated using a RSM model, CCD, BoxBehnken or Doelhert.

- The evaluation of the metaheuristic $g$ function is done for each point performing a set of tests, experiments in RSM terms, on the electromagnetic optimization problem (details in the results section).

- The coefficients of the quadratic function are calculated by LMS (Least Mean Square) method thus obtaining the analytical expression of $g$.

- The optimal set of parameters (considered the point at which $g$ is minimum) is determined by quadratic optimization applied on the analytical expression of $g$.

The complete algorithm can be summarized as follows:

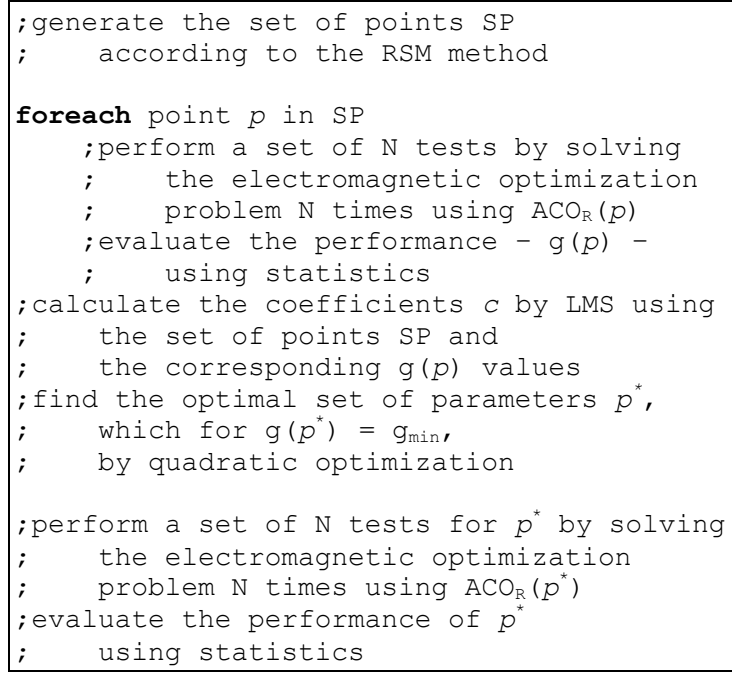

\section{A. The FFD model}

In the Full Factorial Design (FFD) for each variable / parameter of $g$ there are three possible values: minimum, average and maximum. Each parameter value is combined with each value of every other parameter, thus the number 
of points in this model is $N=3^{n p}$. Fig. 2 shows the placement of the points in the FFD model for $n p=3$.

The main drawback of the FFD model appears when the number of parameters is high. For such cases, the number of experiments needed is prohibitive, and this design is therefore not suitable when the evaluation of the OF is expensive.

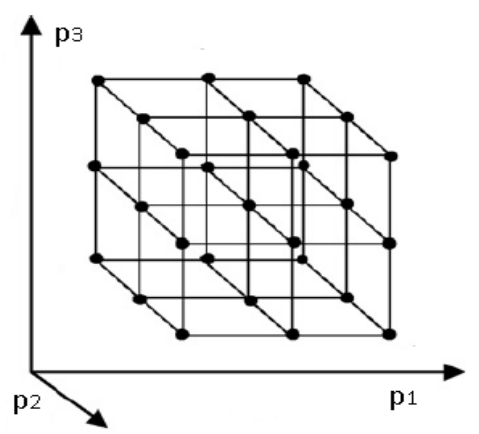

Fig. 2. The points in the FFD model for $n p=3$.

\section{B. The Box-Behnken model}

The Box-Behnken design [15] resides in the FFD model. The points are located inside a hypersphere with the center at the central point of the design space (Fig. 3).

In this design each parameter has three possible values $(-1,0,1)$ scaled respectively to the minimum, average and maximum value of the corresponding $\mathrm{ACO}_{\mathrm{R}}$ parameter. The number of points for this design in the case of our problems, where $n p=4$, is 25 (Appendix - Table V).

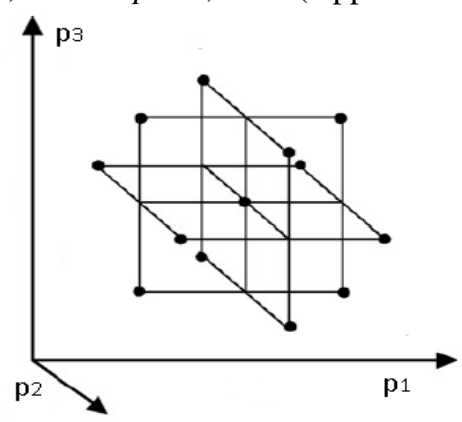

Fig. 3. The points in the Box-Behnken model for $n p=3$.

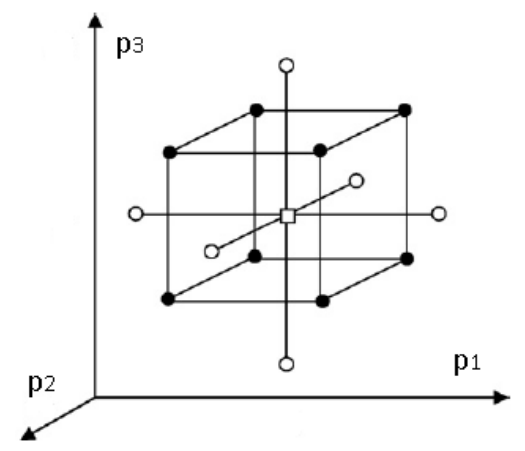

Fig. 4. The points in the CCD model for $n p=3$.

\section{The CCD model}

The CCD model [10] consists of a fractional FFD and a star design both centered in the central point of the design space (Fig. 4).

In the star design the points are set a distance $\alpha$ from the center. Each parameter can have five possible levels ($\alpha,-1,0,1, \alpha)$. The number of points for this design in the case of our problems is 25 (Appendix - Table VI).

\section{The DOELHERT model}

The Doelhert model [16] is the most complex of the RSM models used. Each parameter of the design has a different number of levels, the distance between levels following a uniform distribution. For two parameters the design contains six points and is a hexagon whereas for three parameters contains twelve points and is a cuboctahedron (Fig. 5).

In our case, with four parameters, the design contains 21 points with the coordinates shown in the Appendix Table VII.

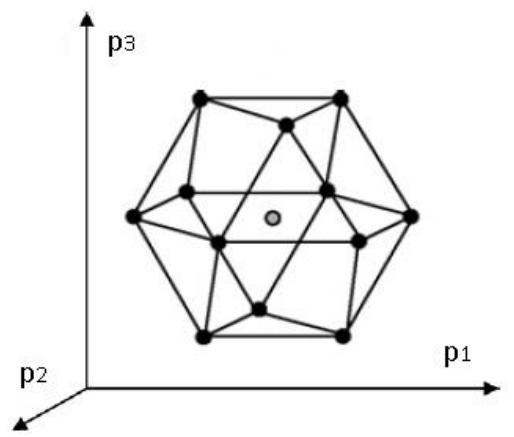

Fig. 5. The points in the Doelhert model for $n p=3$.

\section{ELECTROMAGNETIC BENCHMARK PROBLEMS}

\section{E. The TEAM22 problem}

Two coaxial coils carry current with opposite directions (Fig. 6), operate under superconducting conditions and offer the opportunity to store a significant amount of energy in their magnetic fields, while keeping within certain limits the stray field [17].

An optimal design of the device should therefore couple the value of the energy $E$ to be stored by the system with a minimum stray field $B_{\text {stray. }}$. The two objectives are combined into one objective function:

$$
\begin{gathered}
O F=\frac{B_{\text {stray }}^{2}}{B_{\text {norm }}^{2}}+\frac{\left|E-E_{\text {ref }}\right|}{E_{\text {ref }}}, \\
B_{\text {stray }}^{2}=\frac{\sum_{i=1}^{22}\left|B_{\text {stray }, i}\right|^{2}}{22},
\end{gathered}
$$

where $E_{\text {ref }}=180 \mathrm{MJ}$, and $B_{\text {norm }}=3 \mu \mathrm{T}$.

The objective function has as parameters, the radii $\left(R_{1}\right.$, $\left.R_{2}\right)$, the heights $\left(h_{1}, h_{2}\right)$, the thicknesses $\left(d_{1}, d_{2}\right)$ and the current densities $\left(J_{1}, J_{2}\right)$. Besides domain restrictions, the problem must take into account the following conditions: the solenoids do not overlap each other $\left(R_{1}+d_{1} / 2<R_{2}-d_{2} / 2\right)$, and the superconducting material should not violate the quench condition that links together the value of the current density and the maximum value of magnetic flux density 
$\left(\|I\| \leq(-6.4 \cdot|B|+54.0) A / \mathrm{mm}^{2}\right)$. It is a constrain imposed to the current densities.

The evaluation method of the objective function is based on the Biot-Savart-Laplace formula in which the elliptic integrals are computed by using the King algorithm and numerical integration. Moreover, the optimization problem is reformulated as a one with six parameters, since for a given geometry and a stored energy, the values of the current densities can be computed by deterministic quadratic optimization as in [8] [19].

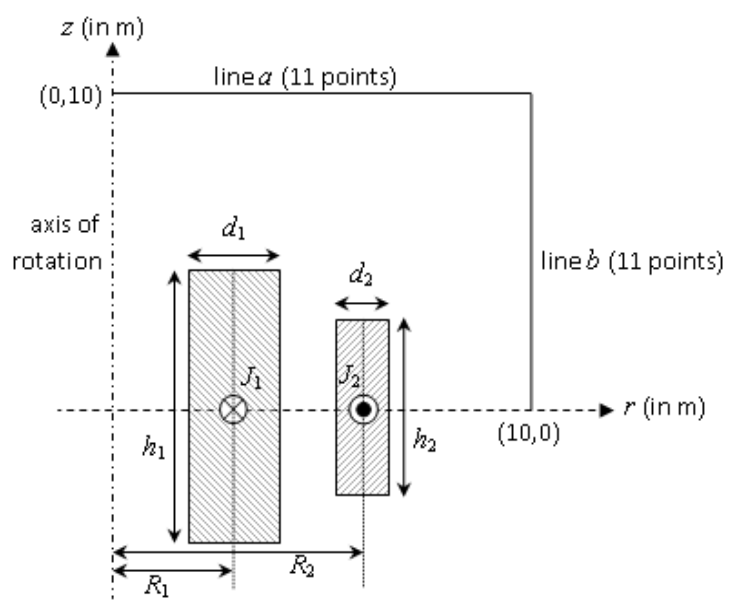

Fig. 6. TEAM22 problem configuration.

\section{F. The Loney's solenoid}

Defined in [18], the Loney's solenoid electromagnetic problem has one main and two correction coils with the following dimensions (Fig. 7): $r_{1}=11 \mathrm{~mm}, r_{2}=29 \mathrm{~mm}, h$ $=120 \mathrm{~mm}, r_{3}=30 \mathrm{~mm}, r_{4}=36 \mathrm{~mm}$. The current density through the coils is the same with the goal of having a density of the magnetic flux constant in the center of the main coil.

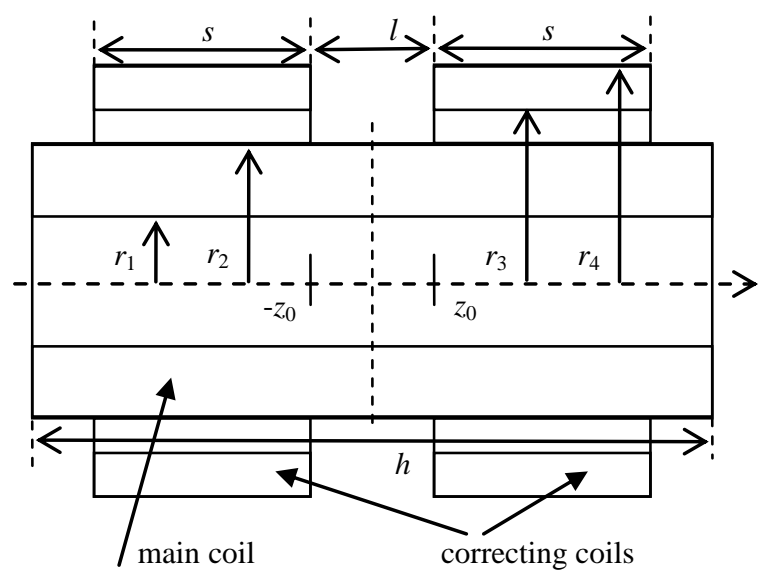

Fig. 7. Loney's solenoid problem configuration.

The objective function to be minimized is $\left(B_{\max }-\right.$ $\left.B_{\min }\right) / B_{0}$, the difference between the magnetic flux densities along a segment in the middle of the main solenoid divided to the density of the magnetic field in the middle of the main coil $(r=0, z=0)$. The maximum / minimum values of the magnetic flux densities are sought along the straight segment $\left[-z_{0}, z_{0}\right], z_{0}=2.5 \mathrm{~mm}$. The optimization problem has two parameters the length $s$ and the distance $l$ between the correction coils.

The implementation details of the Loney's solenoid benchmarks is the same as in the previous papers [8] [19].

\section{RESULTS}

To test the proposed approach two electromagnetic optimization problems were chosen, namely TEAM 22 [17] and Loney's solenoid [18]. The implementation details of the TEAM 22 and Loney's solenoid benchmarks are the same as in the previous papers [8] [19].

For the construction of the metaheuristic function $g$ the variation intervals for the $\mathrm{ACO}_{\mathrm{R}}$ parameters were: the number of ants $a$, integer values between $[2 ; 8]$, the archive size $k$ integers between $[20 ; 60]$, the convergence rate $\xi$ real values between $[0.5 ; 0.99]$, and the locality of the search process $q$ real values between [1E-4; 1E-2].

To evaluate the performance for a set of parameters (evaluation of the $g$ function) two cases were studied, the min-best $\mathrm{OF}$ value and the mean-best $\mathrm{OF}$ value over a set of 30 tests, to make a relevant statistical study. The minbest is the minimum of the minimum (best) values, and the mean-best is the average of the minimum values for the mentioned 30 runs. For each test the stopping criteria was a maximum number of 2560 OF evaluations, a number appearing to be sufficient to reach convergence for the chosen benchmark problems [8] [19].

Tables I-IV present results, the obtained optimal set of parameters and the statistical flags for solving the Loney's solenoid and the TEAM22 problems. The statistical flags are calculated once again on a set of 30 independent runs. The best results previously obtained in [8], where the $\mathrm{ACO}_{\mathrm{R}}$ performance tuning was roughly performed only on the number of ants, are presented as comparison.

For the Loney's solenoid problem when the objective of $g$ is the min-best OF (Table I) the best solution is obtained with the Box-Behnken design. The optimal parameters provided by the design lean towards exploitation, small convergence rate, small archive size, small locality of search process all in favor of the better ranked solutions. Regarding the value of the OF this is one of the best ever reported in the literature.

When the objective of the metaheuristic function is the mean-best OF (Table II) the best RSM design is Doelhert. The optimal set of parameters are very high number of ants, small archive size and small convergence rate (high converge speed) in favor of exploitation and very high search process locality parameter in favor of exploration. In this case, the set of parameters mentioned in [8] lead to a better mean-best.

For the TEAM 22 problem when the goal of $g$ is minbest OF once again the best approach is Box-Benhken (Table III). The results are once again some of the best in the literature in terms of min-best OF. The optimal set of parameters are quite different from the parameters provided by the same design for the Loney's solenoid. However, the parameter values are rather contradictory, very high number of ants and small archive size clearly in favor of exploitation, very high convergence rate (small convergence speed) and very high locality of the search process in favor of exploration.

Finally, when the objective of the metaheuristic function is the mean-best OF (Table IV) just like in the case of Loney's solenoid the optimal set of parameters for TEAM22 is given by the Doelhert design. The results are almost identical with the ones mentioned in [8], in terms of mean-best OF and also in terms of parameter values, small number of ants, large archive size, high convergence 
rate and small locality of the search process, clearly oriented towards exploration.

TABLE I.

RESULTS FOR LONEY'S SOLENOID PROBLEM, WHEN THE METAHEURISTIC OBJECTIVE IS THE MIN-BEST OF

\begin{tabular}{|c|c|c|c|c|}
\hline \multirow{2}{*}{} & \multicolumn{4}{|c|}{ Method } \\
\cline { 2 - 5 } & $\begin{array}{c}\mathrm{CCD} \\
+\mathrm{ACO}_{\mathrm{R}}\end{array}$ & $\begin{array}{c}\text { Box- } \\
\text { Behnken } \\
+\mathrm{ACO}_{\mathrm{R}}\end{array}$ & $\begin{array}{c}\text { Doelhert } \\
+\mathrm{ACO}_{\mathrm{R}}\end{array}$ & ACO $_{\mathrm{R}}[8]$ \\
\hline$a$ & 2 & $\mathbf{4}$ & 3 & 4 \\
\hline$k$ & 34 & $\mathbf{2 6}$ & 60 & 40 \\
\hline$\xi$ & 0.52 & $\mathbf{0 . 5 0}$ & 0.99 & 0.85 \\
\hline$q$ & $10 \mathrm{E}-3$ & $\mathbf{3 . 4 E}-3$ & $9.8 \mathrm{E}-3$ & $1 \mathrm{E}-4$ \\
\hline $\begin{array}{c}\text { Min - best } \\
\text { OF value }\end{array}$ & $3.02 \mathrm{E}-10$ & $\mathbf{1 . 2 4 E}-10$ & $5.68 \mathrm{E}-10$ & $2.22 \mathrm{E}-9$ \\
\hline $\begin{array}{c}\text { Max - best } \\
\text { OF value }\end{array}$ & $2.8 \mathrm{E}-6$ & $2.2 \mathrm{E}-6$ & $2.2 \mathrm{E}-6$ & $6.10 \mathrm{E}-8$ \\
\hline $\begin{array}{c}\text { Mean - best } \\
\text { OF value }\end{array}$ & $6.81 \mathrm{E}-8$ & $9.53 \mathrm{E}-8$ & $1.17 \mathrm{E}-7$ & $1.32 \mathrm{E}-8$ \\
\hline $\begin{array}{c}\text { Standard } \\
\text { deviation }\end{array}$ & $3.09 \mathrm{E}-7$ & $3.29 \mathrm{E}-7$ & $3.78 \mathrm{E}-7$ & $9.78 \mathrm{E}-9$ \\
\hline
\end{tabular}

TABLE II.

RESULTS FOR LONEY'S SOLENOID PROBLEM, WHEN THE METAHEURISTIC OBJECTIVE IS THE MEAN-BEST OF

\begin{tabular}{|c|c|c|c|c|}
\hline \multirow{2}{*}{} & \multicolumn{4}{|c|}{ Method } \\
\cline { 2 - 5 } & $\begin{array}{c}\mathrm{CCD} \\
+\mathrm{ACO}_{\mathrm{R}}\end{array}$ & $\begin{array}{c}\text { Box- } \\
\text { Behnken } \\
+\mathrm{ACO}_{\mathrm{R}}\end{array}$ & $\begin{array}{c}\text { Doelhert } \\
+\mathrm{ACO}_{\mathrm{R}}\end{array}$ & ACO $_{\mathrm{R}}[8]$ \\
\hline$a$ & 2 & 2 & $\mathbf{8}$ & $\mathbf{4}$ \\
\hline$k$ & 20 & 20 & $\mathbf{2 0}$ & $\mathbf{4 0}$ \\
\hline$\xi$ & 0.99 & 0.99 & $\mathbf{0 . 5 3}$ & $\mathbf{0 . 8 5}$ \\
\hline$q$ & $1 \mathrm{E}-2$ & $1.3 \mathrm{E}-3$ & $\mathbf{1 E}-2$ & $\mathbf{1 E}-\mathbf{4}$ \\
\hline $\begin{array}{c}\text { Min - best } \\
\text { OF value }\end{array}$ & $1.67 \mathrm{E}-9$ & $1.21 \mathrm{E}-9$ & $6.92 \mathrm{E}-9$ & $2.22 \mathrm{E}-9$ \\
\hline $\begin{array}{c}\text { Max - best } \\
\text { OF value }\end{array}$ & $5.01 \mathrm{E}-7$ & $4.00 \mathrm{E}-7$ & $8.46 \mathrm{E}-8$ & $6.10 \mathrm{E}-8$ \\
\hline $\begin{array}{c}\text { Mean - best } \\
\text { OF value }\end{array}$ & $2.17 \mathrm{E}-8$ & $2.93 \mathrm{E}-8$ & $\mathbf{1 . 6 1 E - 8}$ & $\mathbf{1 . 3 2 E - 8}$ \\
\hline $\begin{array}{c}\text { Standard } \\
\text { deviation }\end{array}$ & $6.19 \mathrm{E}-8$ & $7.22 \mathrm{E}-8$ & $8.36 \mathrm{E}-9$ & $9.78 \mathrm{E}-9$ \\
\hline
\end{tabular}

TABLE III.

RESULTS FOR TEAM22 PROBLEM, WHEN THE METAHEURISTIC OBJECTIVE IS THE MIN-BEST OF

\begin{tabular}{|c|c|c|c|c|}
\hline \multirow{2}{*}{} & \multicolumn{4}{|c|}{ Method } \\
\cline { 2 - 5 } & $\begin{array}{c}\mathrm{CCD} \\
+\mathrm{ACO}_{\mathrm{R}}\end{array}$ & $\begin{array}{c}\text { Box- } \\
\text { Behnken } \\
+\mathrm{ACO}_{\mathrm{R}}\end{array}$ & $\begin{array}{c}\text { Doelhert } \\
+\mathrm{ACO}_{\mathrm{R}}\end{array}$ & ACO $_{\mathrm{R}}[8]$ \\
\hline$a$ & 2 & $\mathbf{8}$ & 2 & 8 \\
\hline$k$ & 50 & $\mathbf{2 0}$ & 50 & 40 \\
\hline$\xi$ & 0.75 & $\mathbf{0 . 9 9}$ & 0.85 & 0.85 \\
\hline$q$ & $1 \mathrm{E}-4$ & $\mathbf{1 E - 2}$ & $3.2 \mathrm{E}-4$ & $1 \mathrm{E}-4$ \\
\hline $\begin{array}{c}\text { Min - best } \\
\text { OF value }\end{array}$ & $2.09 \mathrm{E}-3$ & $\mathbf{1 . 9 3 E - 3}$ & $2.01 \mathrm{E}-3$ & $2.03 \mathrm{E}-03$ \\
\hline $\begin{array}{c}\text { Max - best } \\
\text { OF value }\end{array}$ & $7.20 \mathrm{E}-3$ & $1.36 \mathrm{E}-2$ & $6.05 \mathrm{E}-3$ & $3.52 \mathrm{E}+00$ \\
\hline $\begin{array}{c}\text { Mean - best } \\
\text { OF value }\end{array}$ & $2.95 \mathrm{E}-3$ & $3.33 \mathrm{E}-3$ & $3.04 \mathrm{E}-3$ & $1.21 \mathrm{E}-01$ \\
\hline $\begin{array}{c}\text { Standard } \\
\text { deviation }\end{array}$ & $1.10 \mathrm{E}-3$ & $2.09 \mathrm{E}-3$ & $9.56 \mathrm{E}-4$ & $6.41 \mathrm{E}-01$ \\
\hline
\end{tabular}

TABLE IV.

RESULTS FOR TEAM22 PROBLEM, WHEN THE METAHEURISTIC OBJECTIVE IS THE MEAN-BEST OF

\begin{tabular}{|c|c|c|c|c|}
\hline \multirow{2}{*}{} & \multicolumn{4}{|c|}{ MBJECTIVE IS THE MEAN-BEST OF } \\
\cline { 2 - 5 } & $\begin{array}{c}\text { CCD } \\
+\mathrm{ACO}_{\mathrm{R}}\end{array}$ & $\begin{array}{c}\text { Box- } \\
\text { Behnken } \\
+\mathrm{ACO}_{\mathrm{R}}\end{array}$ & $\begin{array}{c}\text { Doelhert } \\
+\mathrm{ACO}_{\mathrm{R}}\end{array}$ & $\mathrm{ACO}_{\mathrm{R}}[8]$ \\
\hline$a$ & 2 & 2 & $\mathbf{2}$ & $\mathbf{4}$ \\
\hline$k$ & 49 & 60 & $\mathbf{6 0}$ & $\mathbf{4 0}$ \\
\hline$\xi$ & 0.5 & 0.52 & $\mathbf{0 . 9 9}$ & $\mathbf{0 . 8 5}$ \\
\hline$q$ & $1 \mathrm{E}-2$ & $1 \mathrm{E}-2$ & $\mathbf{1 E}-\mathbf{4}$ & $\mathbf{1 E - 4}$ \\
\hline $\begin{array}{c}\text { Min - best } \\
\text { OF value }\end{array}$ & $2.31 \mathrm{E}-3$ & $2.02 \mathrm{E}-3$ & $2.31 \mathrm{E}-3$ & $2.15 \mathrm{E}-03$ \\
\hline $\begin{array}{c}\text { Max - best } \\
\text { OF value }\end{array}$ & $3.78 \mathrm{E}-2$ & $1.14 \mathrm{E}-2$ & $4.96 \mathrm{E}-3$ & $5.99 \mathrm{E}-03$ \\
\hline $\begin{array}{c}\text { Mean - best } \\
\text { OF value }\end{array}$ & $6.37 \mathrm{E}-3$ & $3.73 \mathrm{E}-3$ & $\mathbf{3 . 0 3 E}-3$ & $\mathbf{2 . 9 7 E - 0 3}$ \\
\hline $\begin{array}{c}\text { Standard } \\
\text { deviation }\end{array}$ & $6.63 \mathrm{E}-3$ & $1.97 \mathrm{E}-3$ & $5.82 \mathrm{E}-4$ & $8.03 \mathrm{E}-04$ \\
\hline
\end{tabular}

TABLE V.

PARAMETER VALUES FOR THE BOX-BEHNKEN METHOD

\begin{tabular}{|c|c|c|c|c|}
\hline & $p_{1}$ & $p_{2}$ & $p_{3}$ & $p_{4}$ \\
\hline 1 & -1 & -1 & 0 & 0 \\
\hline 2 & -1 & 1 & 0 & 0 \\
\hline 3 & -1 & 0 & 0 & -1 \\
\hline 4 & -1 & 0 & 0 & 1 \\
\hline 5 & -1 & 0 & -1 & 0 \\
\hline 6 & -1 & 0 & 1 & 0 \\
\hline 7 & 0 & 0 & -1 & -1 \\
\hline 8 & 0 & 0 & -1 & 1 \\
\hline 9 & 0 & 0 & 1 & -1 \\
\hline 10 & 0 & 0 & 1 & 1 \\
\hline 11 & 0 & -1 & -1 & 0 \\
\hline 12 & 0 & -1 & 1 & 0 \\
\hline 13 & 0 & 1 & -1 & 0 \\
\hline 14 & 0 & 1 & 1 & 0 \\
\hline 15 & 0 & -1 & 0 & -1 \\
\hline 16 & 0 & -1 & 0 & 1 \\
\hline 17 & 0 & 1 & 0 & -1 \\
\hline 18 & 0 & 1 & 0 & 1 \\
\hline 19 & 0 & 0 & 0 & 0 \\
\hline 20 & 1 & -1 & 0 & 0 \\
\hline 21 & 1 & 1 & 0 & 0 \\
\hline 22 & 1 & 0 & 0 & -1 \\
\hline 23 & 1 & 0 & 0 & 1 \\
\hline 24 & 1 & 0 & -1 & 0 \\
\hline 25 & 1 & 0 & 1 & 0 \\
\hline
\end{tabular}

TABLE VI.

\section{PARAMETER VALUES FOR THE CCD METHOD}

\begin{tabular}{|c|c|c|c|c|}
\hline & $p_{1}$ & $p_{2}$ & $p_{3}$ & $p_{4}$ \\
\hline 1 & -2 & 0 & 0 & 0 \\
\hline 2 & -1 & -1 & -1 & -1 \\
\hline 3 & -1 & -1 & -1 & 1 \\
\hline
\end{tabular}




\begin{tabular}{|c|c|c|c|c|}
\hline 4 & -1 & -1 & 1 & -1 \\
\hline 5 & -1 & -1 & 1 & 1 \\
\hline 6 & -1 & 1 & -1 & -1 \\
\hline 7 & -1 & 1 & -1 & 1 \\
\hline 8 & -1 & 1 & 1 & -1 \\
\hline 9 & -1 & 1 & 1 & 1 \\
\hline 10 & 0 & -2 & 0 & 0 \\
\hline 11 & 0 & 2 & 0 & 0 \\
\hline 12 & 0 & 0 & -2 & 0 \\
\hline 13 & 0 & 0 & 2 & 0 \\
\hline 14 & 0 & 0 & 0 & -2 \\
\hline 15 & 0 & 0 & 0 & 2 \\
\hline 16 & 0 & 0 & 0 & 0 \\
\hline 17 & 1 & -1 & -1 & -1 \\
\hline 18 & 1 & -1 & -1 & 1 \\
\hline 19 & 1 & -1 & 1 & -1 \\
\hline 20 & 1 & -1 & 1 & 1 \\
\hline 21 & 1 & 1 & -1 & -1 \\
\hline 22 & 1 & 1 & -1 & 1 \\
\hline 23 & 1 & 1 & 1 & -1 \\
\hline 24 & 1 & 1 & 1 & 1 \\
\hline 25 & 2 & 0 & 0 & 0 \\
\hline
\end{tabular}

TABLE VII.

PARAMETER VALUES FOR THE DOELHERT METHOD

\begin{tabular}{|c|c|c|c|c|}
\hline & $p_{1}$ & $p_{2}$ & $p_{3}$ & $p_{4}$ \\
\hline 1 & -1 & 0 & 0 & 0 \\
\hline 2 & -0.5 & -0.86603 & 0 & 0 \\
\hline 3 & -0.5 & -0.28868 & -0.8165 & 0 \\
\hline 4 & -0.5 & -0.28868 & -0.20412 & -0.79057 \\
\hline 5 & -0.5 & 0.866025 & 0 & 0 \\
\hline 6 & -0.5 & 0.288675 & 0.816497 & 0 \\
\hline 7 & -0.5 & 0.288675 & 0.204124 & 0.790569 \\
\hline 8 & 0 & 0 & 0 & 0 \\
\hline 9 & 0 & 0.57735 & -0.8165 & 0 \\
\hline 10 & 0 & 0.57735 & -0.20412 & -0.79057 \\
\hline 11 & 0 & -0.57735 & 0.816497 & 0 \\
\hline 12 & 0 & 0 & 0.612372 & -0.79057 \\
\hline 13 & 0 & -0.57735 & 0.204124 & 0.790569 \\
\hline 14 & 0 & 0 & -0.61237 & 0.790569 \\
\hline 15 & 0.5 & 0.866025 & 0 & 0 \\
\hline 16 & 0.5 & 0.288675 & 0.816497 & 0 \\
\hline 17 & 0.5 & 0.288675 & 0.204124 & 0.790569 \\
\hline 18 & 0.5 & -0.86603 & 0 & 0 \\
\hline 19 & 0.5 & -0.28868 & -0.8165 & 0 \\
\hline 20 & 0.5 & -0.28868 & -0.20412 & -0.79057 \\
\hline 21 & 1 & 0 & 0 & 0 \\
\hline
\end{tabular}

\section{CONCLUSIONS}

Following the proposal from [21], the present paper studied the effectiveness of improving the performance of the $\mathrm{ACO}_{\mathrm{R}}$ evolutionary algorithm by using RSM strategies for solving electromagnetic benchmark problems. To test and verify the proposed enhancement two electromagnetic benchmarks were chosen, namely TEAM22 and Loney's solenoid.

The enhancement is performed by searching the optimal set of $\mathrm{ACO}_{\mathrm{R}}$ parameters. To achieve this goal a metaheuristic quadratic function in the parameters space is constructed using RSM methods, namely CCD, BoxBehnken and Doelhert. For the evaluation of the metaheuristic function two different objectives were studied: the minimum best (min-best) value and the average best (mean-best) value of the original OF over a statistical set of tests.

The results obtained with the proposed approach were compared to previously obtained results from [8], where the $\mathrm{ACO}_{\mathrm{R}}$ 's performance was tunned roughly, only on one parameter namely the ants number.

When the objective of the metaheuristic function is the min-best value of the original OF the Box-Behnken design generates the best set of optimal parameters from all the design strategies for both electromagnetic benchmarks. The values obtained for the OF are from author's knowledge some of the best found in the literature for TEAM22 and also Loney's solenoid.

When the objective of the metaheuristic function is the mean-best value of the original OF the Doelhert design is the most suitable for both electromagnetic problems. However, the obtained results are comparable with results obtained in [8] in the case of TEAM22 and a little poorer than the results in [8] in the case of Loney's solenoid.

\section{ACKNOWLEDGMENT}

The authors acknowledge the support of our colleague and Professor Gabriela Ciuprina, who has provided the implementation codes for the Loney's solenoid and TEAM22 electromagnetic benchmark problems.

Contribution of authors:

First author $-67 \%$

First coauthor $-33 \%$

Received on July 17,2021

Editorial Approval on November 15, 2021

\section{REFERENCES}

[1] M. Dorigo, V. Maniezzo and A. Colorni, Ant system: optimization by a colony of cooperating agents, IEEE Transactions on Systems, Man, and Cybernetics, Part B (Cybernetics), 26(1), pp. 29-41, 1996.

[2] T. Stutzle, and H. Hoos, MAX-MIN ant system and local search for the traveling salesman problem, IEEE Evolutionary Computation, pp. 309-314, 1997.

[3] M. Dorigo, and G. Di Caro, Ant colony optimization: a new metaheuristic, Proceedings of the Congress on Evolutionary Computation, pp. 1470-1477, 1999.

[4] E. Ridge, and D. Kudenko. Tuning the performance of the MMAS heuristic. In Engineering stochastic local search algorithms. designing, implementing and analyzing effective heuristics, pp. 4660. Springer, Berlin, Heidelberg, 2007.

[5] S. Fidanova,, Ant colony optimization and multiple knapsack problem. In Handbook of Research on Nature-Inspired Computing for Economics and Management, pp. 498-509. IGI Global, 2007.

[6] L. Ke, Qingfu. Zhang, and R. Battiti, MOEA/D-ACO: A multiobjective evolutionary algorithm using decomposition and antcolony. IEEE Transactions on Cybernetics, 43(6), pp. 1845-1859, 2013. 
[7] K. Socha, and M. Dorigo, Ant colony optimization for continuous domains, European journal of operational research, 185(3), pp.1155-1173, 2008.

[8] Duca, A., Ciuprina, G., Lup, S. and Hameed, I., 2019, March. $\mathrm{ACO}_{\mathrm{R}}$ algorithm's efficiency for electromagnetic optimization benchmark problems. In 2019 11th International Symposium on Advanced Topics in Electrical Engineering (ATEE) (pp. 1-5).

[9] Myers, Raymond H., Douglas C. Montgomery, and Christine M. Anderson-Cook. Response surface methodology: process and product optimization using designed experiments. John Wiley \& Sons, 2016.

[10] Box, G.E. and Wilson, K.B., 1951. On the experimental attainment of optimum conditions. Journal of the royal statistical society: Series $b$ (Methodological), 13(1), pp.1-38.

[11] Bezerra, M.A., Santelli, R.E., Oliveira, E.P., Villar, L.S. and Escaleira, L.A., 2008. Response surface methodology (RSM) as a tool for optimization in analytical chemistry. Talanta, 76(5), pp.965-977.

[12] Leuca, T., Trip, N.D., Silaghi, H. and Burca, A.D.R.I.A.N., 2016. Design of experiments approach for induction heating optimization. Revue roumaine des sciences techniques, Série Électrotechnique et Énergétique, 61(2), pp.169-172.

[13] Rong, Ruowen, David A. Lowther, Zahid Malik, Hua Su, J. Nelder, and R. Spence. "Applying response surface methodology in the design and optimization of electromagnetic devices." IEEE Transactions on magnetics 33, no. 2 (1997): 1916-1919.
[14] Gillon, Frederic, and Pascal Brochet. "Screening and response surface method applied to the numerical optimization of electromagnetic devices." IEEE transactions on magnetics 36 , no. 4 (2000): 1163-1167.

[15] Box, G.E. and Behnken, D.W., 1960. Some new three level designs for the study of quantitative variables. Technometrics, 2(4), pp.455-475.

[16] Doehlert, D.H., 1970. Uniform shell designs. Journal of the Royal Statistical Society: Series C (Applied Statistics), 19(3), pp.231239.

[17] TEAM22 benchmark problem - international COMPUMAG society. http://www.compumag.org/wp/team.

[18] P. Di Barba, A. Gottvald, A. Savini, Global optimization of Loney's solenoid: A benchmark problem. International Journal of Applied Electromagnetics and Mechanics, 6(4), pp. 273-276, 1995.

[19] Duca, A., Duca, L., Ciuprina, G. and Ioan, D., 2016, November. Neighborhood Strategies for QPSO Algorithms to Solve Benchmark Electromagnetic Problems. In International Conference on Evolutionary Computation Theory and Applications (Vol. 2, pp. 148-155). SCITEPRESS.

[20] Ciuprina, G., Ioan, D. and Munteanu, I., 2002. Use of intelligentparticle swarm optimization in electromagnetics. IEEE Transactions on Magnetics, 38(2), pp.1037-1040.

[21] Duca, A. RSM enhanced $\mathrm{ACO}_{\mathrm{R}}$ algorithm for electromagnetic optimization. In2021 International Conference on Applied and Theoretical Electricity (ICATE) 2021 May 27 (pp. 1-5). IEEE. 